\title{
Drug-resistant bacteria go undetected
}

\author{
Poor training in use of tests allows 'superbugs' to evade surveillance.
}

Daniel Cressey

\section{April 2012}

Efforts to detect and halt the global spread of drug-resistant bacteria are being hindered by a poor understanding of the limitations of crucial laboratory tests. Because infected patients need to be isolated quickly to avoid spreading infections, the failure to identify antibiotic-resistant pathogens is increasing the risk of untreatable outbreaks, microbiologists argue.

This month at the European Congress of Clinical Microbiology and Infectious Diseases in London, Herman Goossens, director of the Laboratory of Medical Microbiology at the Vaccine and Infectious Disease Institute of the University of Antwerp in Belgium, presented data about one type of commercial kit often used to identify particular drug-resistant pathogens ${ }^{1}$.

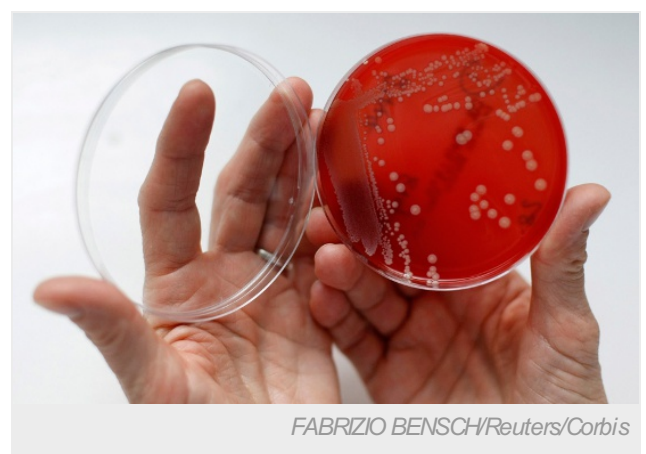

Antibiotic-resistant bacteria are slipping through scientists' fingers.

The tests contain mixtures of chemicals that encourage some bacteria to grow and discourage others. Samples from stools or rectal swabs are streaked across the growth medium on a plate and then left overnight. The next day, different-coloured growths indicate the presence of different species of resistant bacteria.

\section{Under the radar}

One type of bacterium that is causing concern carries genetic mutations that cause it to produce carbapenemase enzymes, which confer resistance to carbapenem antibiotics. Health agencies around the world have reported a surge in infections involving carbapenem-resistant bacteria over the past decade. Another worrying mutation produces extended-spectrum $\beta$-lactamases (ESBLs), which are resistant to cephalosporin drugs.

An example of the difficulties with identifying these bacteria, Goossens says, is a common test for carbapenem-resistant bacteria using plates made by CHROMagar, a microbiology company based in Paris. The plates detect only high levels of carbapenem resistance, meaning that laboratories may fail to detect bacteria with low but clinically important levels of resistance, he says.

The company is not selling a defective test, and is open about the limitations of its media. Alberto Lerner, general manager of CHROMagar, says that although it is possible that some pathogens will fail to grow on certain media, it is normal practice to back up a test for any particular bacterium by using more than one detection method. "We think all the users are fully aware of how to use them," he said of his company's products.

However, some researchers think that poor training has left microbiologists unaware of how best to interpret test results. Kenneth Thomson, director of the Center for Research in Anti-infectives and Biotechnology at Creighton University in Omaha, Nebraska, says that an ongoing "de-skilling" of microbiology laboratories in Europe and the United States is problematic. He says that lab directors with $\mathrm{PhDs}$ are not being replaced when they leave, and that budget constraints are cutting continuing education for laboratory staff.

Patrice Nordmann, head of bacteriology, virology and parasitology at the Bicêtre Hospital in Paris, agrees that many laboratory workers are missing the presence of carbapenemase-producing bacteria in samples. "The specialists, they know there is a problem. Those who are not specialists use media that are not always very well adapted to this screening," says Nordmann.

This year, Nordmann published a paper ${ }^{2}$ describing a screening medium with a new set of constituent chemicals that is apparently more effective at detecting carbapenemases than existing media. He is now in discussions with a number of companies about commercializing the test.

\section{Get the word out}

Goossens argues that manufacturing companies could help by revealing the exact composition of their media, which might help 
researchers to improve their understanding of the tests' limitations. He suggests that an independent group of researchers should be set up to produce guidelines and recommendations on the use of various culture media, and to perform independent effectiveness tests.

Lerner says that disclosing the exact composition of his company's products would only make it easier for rogue companies to steal CHROMagar's innovations. "From my experience, routine users of our media are not really interested in knowing their composition, but in their performances, limitations and how to use these tools," he says.

bioMérieux, another major manufacturer of these products, based in Marcy L'Étoile, France, also insists that the exact constitution of plates needs to remain a commercial secret, and that this does not affect their safe use.

Thomson says that regulatory bodies such as the Clinical and Laboratory Standards Institute in Wayne, Pennsylvania, have been slow to respond to problems with tests. He notes that 29 years after ESBLs were first reported, the United States has guidelines for identifying only four of them.

"For some patients, we are already in the era of the septic ward where there is no effective antibacterial therapy available, and all that health professionals can do is observe to see if the patient recovers or dies," he says.

Nature | doi:10.1038/nature.2012.10544

\section{References}

1. Carrër, A., Fortineau, N. \& Nordmann, P. J. Clin. Microbiol. 48, 1913-1914 (2010).

2. Nordmann, P., Girlich, D. \& Poirel, L. J. Clin. Microbiol. http://dx.doi.org/10.1128/JCM.06477-11 (2012). 